\title{
Covid-19 e a Necessidade de Ressignificação do Ensino de Epidemiologia nas Escolas Médicas: O Que Nos Ensinam as Diretrizes Curriculares Nacionais?
}

\section{Covid-19 and the Need to reframe Epidemiology Teaching in Medical Schools: What Do National Curriculum Guidelines Teach Us?}

\author{
Carlos Dornels Freire de Souza $a^{I}$ (iD \\ Michael Ferreira Machado ${ }^{I}$ (D) \\ Divanise Suruagy Correia ${ }^{I I} \mathbb{D}$ \\ Olavo Franco Ferreira Filho ${ }^{I I I}$ (D)
}

Caro Editor,

No apagar das luzes de 2019, a China reportou à Organização Mundial da Saúde (OMS) a ocorrência de um surto de pneumonia na cidade de Wuhan, capital da província de Hubei. Causada por um novo coronavírus, batizado de Sars-CoV-2, a doença rapidamente ultrapassou os limites territoriais da China e se espalhou pelo mundo. Em 30 de janeiro de 2020, a OMS declarou "Emergência de Saúde Pública de Importância Internacional”", e, em 11 de março, foi decretada a pandemia causada pela nova doença ${ }^{3}$.

Em 14 de abril de 2020, já havia 1.844 .863 casos confirmados (um acréscimo de 71.779 em relação ao dia anterior) e 117.021 mortes (um acréscimo de 5.369 em 24 horas), com risco global classificado como "muito alto". O Brasil ocupa a terceira posição entre os países das Américas em número de casos confirmados (22.169) e de óbitos $(1.223)^{4}$. Salienta-se que esses números estão em intenso crescimento.

Diante do quadro de calamidade pública, sobre o qual se tem pouco (ou quase nenhum) conhecimento, e considerando que as decisões sobre ele (se equivocadas) podem trazer consequências dramáticas para a população, a epidemiologia se reveste da máxima importância. No entanto, embora os cursos de pós-graduação do país formem profissionais de excelência, a epidemiologia, no âmbito da graduação, tem sido muitas vezes colocada em segundo plano (uma disciplina secundária diante das desejadas clínicas médica e cirúrgica).

Essa subvalorização no campo prático não dialoga com as Diretrizes Curriculares Nacionais do curso de graduação em Medicina - DCN (Resolução no 3, de 20 de junho de 2014) ${ }^{5}$, tampouco com a importância da disciplina para a sociedade ${ }^{6}$. Nas DCN, são feitas seis menções expressas à epidemiologia, reforçando a importância da disciplina para a formação médica contemporânea, conforme apresentamos a seguir ${ }^{4}$.

\section{Citação 1}

Art. $5^{\circ} \mathrm{Na}$ Atenção à Saúde, o graduando será formado para considerar sempre as dimensões da diversidade biológica, subjetiva, étnico-racial, de gênero, orientação sexual, socioeconômica, política, ambiental, cultural, ética e demais aspectos que compõem o espectro da diversidade humana que singularizam cada pessoa ou cada grupo social, no sentido de concretizar:

$[\ldots]$

IV - segurança na realização de processos e procedimentos, referenciados nos mais altos padrões da prática médica, de modo a evitar riscos, efeitos adversos e danos aos usuários, a si mesmo e aos profissionais do sistema de saúde, com base em reconhecimento clínico-epidemiológico, nos riscos e vulnerabilidades das pessoas e grupos sociais (grifo nosso).

\section{Citações 2 e 3}

Art. 12. A ação-chave Identificação de Necessidades de Saúde comporta os seguintes desempenhos e seus respectivos descritores:

I - Realização da História Clínica:

$[\ldots]$

g) orientação e organização da anamnese, utilizando o raciocínio clínico-epidemiológico, a técnica

\footnotetext{
${ }^{\mathrm{I}}$ Universidade Federal de Alagoas, Arapiraca, Alagoas, Brasil.

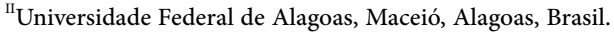

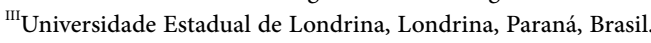


semiológica e o conhecimento das evidências científicas;

[...]

III - Formulação de Hipóteses e Priorização de Problemas:

$[\ldots]$

b) prognóstico dos problemas da pessoa sob seus cuidados, considerando os contextos pessoal, familiar, do trabalho, epidemiológico, ambiental e outros pertinentes [...] (grifo nosso).

\section{Citação 4}

Art. 13. A ação-chave Desenvolvimento e Avaliação de Planos Terapêuticos comporta os seguintes desempenhos e seus respectivos descritores:

I - Elaboração e Implementação de Planos Terapêuticos:

a) estabelecimento, a partir do raciocínio clínico-epidemiológico em contextos específicos, de planos terapêuticos, contemplando as dimensões de promoção, prevenção, tratamento e reabilitação [...] (grifo nosso).

\section{Citação 5}

Art. 14. A ação-chave Investigação de Problemas de Saúde Coletiva comporta o desempenho de Análise das Necessidades de Saúde de Grupos de Pessoas e as Condições de Vida e de Saúde de Comunidades, a partir de dados demográficos, epidemiológicos, sanitários e ambientais, considerando dimensões de risco, vulnerabilidade, incidência e prevalência das condições de saúde, com os seguintes descritores: [...] (grifo nosso).

\section{Citação 6}

Art. 23. Os conteúdos fundamentais para o Curso de Graduação em Medicina devem estar relacionados com todo o processo saúdedoença do cidadão, da família e da comunidade e referenciados na realidade epidemiológica e profissional, proporcionando a integralidade das ações do cuidar em saúde, contemplando: [...] (grifo nosso).

A partir de então, as DCN nos dão três ensinamentos fundamentais para ressignificar o ensino de epidemiologia nas escolas médicas. Mas, antes disso, devemos partir de dois conceitos fundamentais, o de epidemiologia e o do verbo ressignificar. Por epidemiologia compreende-se o estudo do processo saúde-doença numa população, buscando analisar a frequência e distribuição dos problemas de saúde e os fatores determinantes com o intuito de indicar (e posteriormente avaliar) o caminho a ser tomado pelos governos na promoção de uma vida saudável ${ }^{7}$.

Já a palavra ressignificar traz consigo a ideia de atribuir um novo sentido, conferir uma nova forma de perceber a realidade ${ }^{8}$. Neste texto, a ideia de ressignificar a epidemiologia não significa apenas situá-la no lugar de direito, mas também deslocá-la para o tabuleiro das habilidades e competências dos sujeitos sociais que atuam no processo saúde-doença, com destaque para o papel do médico.

O primeiro ensinamento trazido pelas DCN está na última citação (citação 6), que diz respeito à estrutura curricular fundamental da graduação médica. Nela, a epidemiologia aparece como alicerce da formação, visto que todo o processo de ensino deve fundamentar-se na realidade epidemiológica na qual o curso está inserido9. Portanto, o currículo deve ser continuamente renovado ${ }^{8}$. O conhecimento epidemiológico é dinâmico tal como a realidade social. Em três meses, a Covid-19 nos fez refletir sobre a nossa própria existência, a importância da ciência, da solidariedade e da brevidade da vida, além de nos colocar distantes dos nossos familiares e amigos.

\section{"O que era ontem hoje não mais o é."}

O segundo ensinamento refere-se à importância do pensamento epidemiológico na formação do clínico. Embora a epidemiologia e a clínica tenham objetos e métodos diferentes, elas são interdependentes. A epidemiologia orienta a clínica, e esta nutre aquela, numa relação interespecífica, harmônica e mutualística. $\mathrm{O}$ resultado é um bem comum social, a saúde da população.

\section{"A epidemiologia orienta a clínica, e esta nutre aquela."}

A formação médica está assentada em três pilares: atenção à saúde, gestão em saúde e educação em saúde ${ }^{5}$. Na dimensão da atenção à saúde, o raciocínio clínico-epidemiológico é uma estratégia capaz de elevar os padrões da prática médica, pois pode contribuir para a identificação das necessidades de saúde, o que envolve a realização da história clínica, a formulação de hipóteses, a priorização de problemas e a elaboração e implementação de planos terapêuticos, expressando-se em habilidades e atitudes fundamentais à beira do leito ${ }^{10}$. Diante do contexto experimentado pelos profissionais de saúde (caracterizado pela abissal falta de recursos e pelos insipientes saberes sobre a Covid-19 e suas consequências), essas habilidades médicas se revestem da máxima importância, pois trazem implicações para o controle da pandemia.

"Somente a combinação do raciocínio clínico com o epidemiológico pode formar um médico de excelência e apto para situações de emergência em saúde pública, como a atual pandemia."

A importância da epidemiologia não pode ficar apenas no campo das necessidades individuais, já que tem no coletivo a sua essência (esse é o terceiro ensinamento). O clínico, no âmbito da atuação comunitária, deve ter competências e habilidades para compreender as necessidades coletivas de saúde. É fundamental que o profissional seja capaz de utilizar dados secundários para a compressão do contexto sociossanitário, relacionar dados e informações com aspectos biológicos, psicológicos, sociais, econômicos e culturais, realizar o diagnóstico comunitário de saúde, priorizar problemas, definir estratégias de intervenção e monitorar os efeitos das ações ${ }^{5}$. Diante da pandemia, essas habilidades/competências estão sendo exigidas dos profissionais que atuam na atenção primária à saúde (APS). A questão central (e de resposta complexa) é:

- Os profissionais de saúde estão conseguindo avançar nos cuidados comunitários diante da pandemia?

O desenvolvimento dessas habilidades e competências não ocorre rapidamente. Elas demandam tempo. Por essa razão, o processo de aquisição do raciocínio clínico-epidemiológico deve iniciar na graduação, com a adoção de metodologias diversas ${ }^{11}$. É comum o raciocínio epidemiológico ficar restrito a uma disciplina no início do curso médico e muito pouco trabalhado nas disciplinas do ciclo profissionalizante, que o reduzem à apresentação de dados epidemiológicos nos primeiros slides 
de cada aula, não havendo conexão com os conhecimentos adquiridos na clínica, que deveriam ser apre(e)ndidos na prática com os conceitos epidemiológicos.

"Necessitamos de uma nova realidade última.

A atual não mais é suficiente."

Isso posto, concluímos este texto retomando o título. É necessário um movimento de ressignificação do ensino de epidemiologia ( $e$ do pensamento epidemiológico) nas escolas médicas brasileiras. Cada vez mais estamos experienciando novas dinâmicas sociais, econômicas, demográficas, culturais e políticas que afetam o perfil sanitário, tornando dinâmico e polissêmico o trabalho médico. Para essas novas demandas, a combinação do raciocínio clínico com o epidemiológico nos parece uma salvaguarda.

\section{REFERÊNCIAS}

1. Zhu N, Zhang D, Wang W, Li X, Yang B, Song J, et al. A novel coronavirus from patients with pneumonia in China, 2019. N. Engl. j. med. 2020;382:727-33. doi: 10.1056/NEJMoa2001017.

2. World Health Organization. Novel Coronavirus(2019-nCoV) Situation Report - 11. WHO; 2020 [acesso em 30 abr 2020]. Disponível em: https://www.who.int/docs/default-source/coronaviruse/situationreports/20200131-sitrep-11-ncov.pdf?sfvrsn=de7c0f7_4.

3. World Health Organization. Novel Coronavirus(2019-nCoV) Situation Report - 51. WHO; 2020 [acesso em 3 abr 2020]. Disponível em: https://www.who.int/docs/default-source/coronaviruse/situationreports/20200311-sitrep-51-covid-19.pdf?sfvrsn=1ba62e57_10.

4. World Health Organization. Coronavirus disease 2019 (COVID-19) Situation Report - 85 [acesso em 15 abr 2020]. Disponível em: https://www.who.int/docs/default-source/coronaviruse/situationreports/20200414-sitrep-85-covid-19.pdf?sfvrsn=7b8629bb_4.

5. Brasil. Ministério da Educação. Diretrizes Curriculares Nacionais do Curso de Graduação em Medicina [acesso em 18 abr 2020]. Disponível em: http://portal.mec.gov.br/cne/. arquivos/pdf/Med.pdf.

6. Fine PEM, Goldacre BM, Haines A. Epidemiology - a science for the people. The Lancet. 2013;381:1249-52. doi: 10.1016/S01406736(13)60766-7.
7. Frérot M, Lefebvre A, Aho S, Callier P, Astruc K, Glélé LSA. What is epidemiology? Changing definitions of epidemiology. 1978-2017. PLoS One. 2018;13(2):e0208442. doi:10.1371/journal.pone.0208442.

8. Medeiros I, Santos R. O processo cognitivo de construção das metáforas conceptuais: ressignificando a aprendizagem. Quipus. 2015;4(1):23-31 [acesso em 18 abr 2020]. Disponível em: https:// repositorio.unp.br/index.php/quipus/article/view/916.

9. Souza CDF, Correia DS, Araújo MDP, Wanderley RA, Machado MF. E o passado é uma roupa que não nos serve mais: uma reflexão sobre integração ensino-saúde-comunidade em curso médico do Nordeste. Rev. bras. educ. med. 2019;43(1):7-11. doi: 10.1590/1981-5271v43suplemento1-editorial.

10. Nunes SOV, Muraguchi EMO, Ferreira Filho OFF, Pontes RMA, Cardoso LTQ, Grion CMC, et al. O ensino de habilidades e atitudes: um relato de experiências. Rev. bras. educ. med. 2013;37(1):126-31. doi: 10.1590/S0100-55022013000100018.

11. Souza CDF, Antonelli BA, Oliveira D. Metodologias ativas de ensino aprendizagem na formação de profissionais da saúde. Rev. Univ. Val. Rio Verd. 2016;14(2):659-77 [acesso em 18 abr 2020]. Disponível em: http:// periodicos.unincor.br/index.php/revistaunincor/article/view/3135.

\section{CONTRIBUIÇÃO DOS AUTORES}

Souza CDF, Correia DS, Machado MF, Ferreira Filho OF participaram da concepção, delineamento, análise e interpretação dos dados, escrita do manuscrito e revisão crítica do conteúdo. Todos os autores aprovam a versão final a ser publicada.

\section{CONFLITO DE INTERESSES}

Sem conflitos de interesses.

\section{ENDEREÇO PARA CORRESPONDÊNCIA}

Carlos Dornels Freire de Souza

Universidade Federal de Alagoas, Departamento de Medicina

Rodovia AL-115, s/n, Bom Sucesso

CEP 57309-005, Arapiraca - AL

E-mail: carlos.freire@arapiraca.ufal.br. 